\title{
Henoch-Schonlein Purpura in an Elderly Women Presenting with Severe GI Bleeding: A case report
}

\author{
MAJ CHOWDHURY ${ }^{\mathrm{a}}$, SM ARAFAT ${ }^{\mathrm{b}}$, ABED HUSSAIN ${ }^{\mathrm{c}}$
}

\begin{abstract}
Summary:
A 65-year-old lady presented with recent onset of purpuric rash over the lower limbs, polyarthritis, severe colicky abdominal pain associated with bloody diarrhea following a short episode of upper respiratory tract infection. Henoch-Schonlein purpura (HSP) was
\end{abstract}

\section{Introduction}

Henoch-Schonlein purpura (HSP) is a non thrombocytopenic purpura and systemic vasculitis of childhood, ${ }^{1}$ that occurs twice as often in males then in females. Heberden and William first described Henoch-Schonlein purpura in the early $19^{\text {th }}$ century. ${ }^{2}$ This mainly affects children between 4 and 11 years. ${ }^{3}$ Annual incidence is 14 cases per 100,000 people and occurs more frequently in the spring and fall. ${ }^{3} 4 \mathrm{It}$ may present as a triad of symptoms: palpable purpuric rash especially on the lower extremities, abdominal pain or renal involvement and arthritis.

There are only few reported cases of HSP in adults. In this citation an elderly lady who presented with severe GI bleeding and extensive erythematous skin rash in addition to joint and abdominal pain but with minimal renal involvement is reported.

\section{Case History}

A 65-year-old Bangladeshi woman, well controlled hypertensive for seven years, presented with 5 days history of painful swelling of multiple joints and erythematous rashes coalescing together giving rise to large blotchy patches on her lower extremities which gradually involved the whole body. This was followed by colicky abdominal pain with post prandial exacerbation and passage of profuse bloody

a. Dr. M A Jalil Chowdhury FCPS, MD, FACP, Associate Professor

b. Dr. SM Arafat FCPS, Asst. Professor

c. Dr. Abed Hussain MBBS, Medical officer

Department of Medicine, Bangabandhu Sheikh Mujib Medical University, Dhaka.

Address of Correspondence: Dr. M A Jalil Chowdhury FCPS, MD, FACP, Associate Professor, Department of Medicine, Bangabandhu Sheikh Mujib Medical University, Dhaka.

Received: 15 May, 2007

Accepted: 6 April, 2008 diagnosed on the basis of normal platelet count, normal serum complement, leucocytoclastic vasculitis on skin biopsy and negative search for rheumatoid factor (RF), antinuclear antibody (ANA), hepatitis $B$ and $C$ virus markers and other infective causes.

(J Bangladesh Coll Phys Surg 2008; 26: 100-102)

stool. She had two episodes of haemoptysis within three days of her illness.

On clinical examination she was afebrile, anxious and uncomfortable with abdominal and joint pain. Skin was marked by tender palpable erythematous maculopapular rashes all over the body which were non-blanching and non-itchy. Both ankle and knee joints were swollen, tender, warm with mild effusion. Abdomen was diffusely tender without any organomegaly.Bowel sound was present. Neither lymphadenopathy nor bony tenderness was present. Examination of other systems was unrevealing. Funduscopy revealed no abnormality.

Laboratory investigation showed raised WBC count of 16700 with $90 \%$ neutrophill. Except raised serum IgA other laboratory profile including ESR, platelet count, liver function test, renal function test, coagulation profile were normal. ANA, antinuclear cytoplasmic antibody (ANCA), RF, HBV and HCV markers were negative. Routine urine examination revealed mild proteinuria, few red blood cells and pus cells but no cast. Twenty four hours urinary total volume (UTV), urinary total protein (UTP) and creatinine clearance rate $(\mathrm{CCr})$ were within normal range. Stool examination showed plenty RBC per high power field (HPF). Colonoscopy showed patchy ulceration with normal appearing intervening mucosa (Fig. 1). Abdominal ultrasound was unremarkable. Skin biopsy showed granular deposition of $\operatorname{IgA}$ and C3 along the dermal capillary wall but no deposition of IgG, IgM or fibrin. With these clinical and laboratory scenarios this patient was diagnosed as a case HSP and was initially treated with intravenous methyl prednisolone $1 \mathrm{gm}$ daily for three consecutive days. There was marked improvement of abdominal and joint pain; skin lesions gradually faded away and 
GI bleeding was stopped. Oral prednisolone was started 3 days after IV steroid but unfortunately quick tapering of steroid resulted in reappearance of abdominal pain, skin lesions and passage of fresh per rectal bleeding. At this stage parenteral hydrocortisone was started and continued for 4 days followed by oral prednisolone. With this her condition was improved dramatically. Repeat colonoscopy revealed no more evidence of colitis (Fig. 2). She was discharged with gradual tapering of prednisolone and he is being monitored for development of any possible complications especially of renal origin.
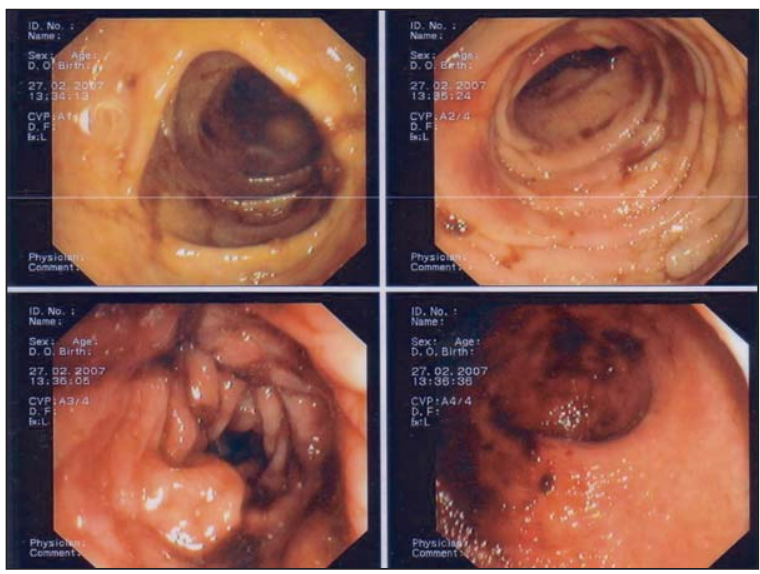

Fig.-1: Colonoscopic findings of vasculitic colitis in HSP
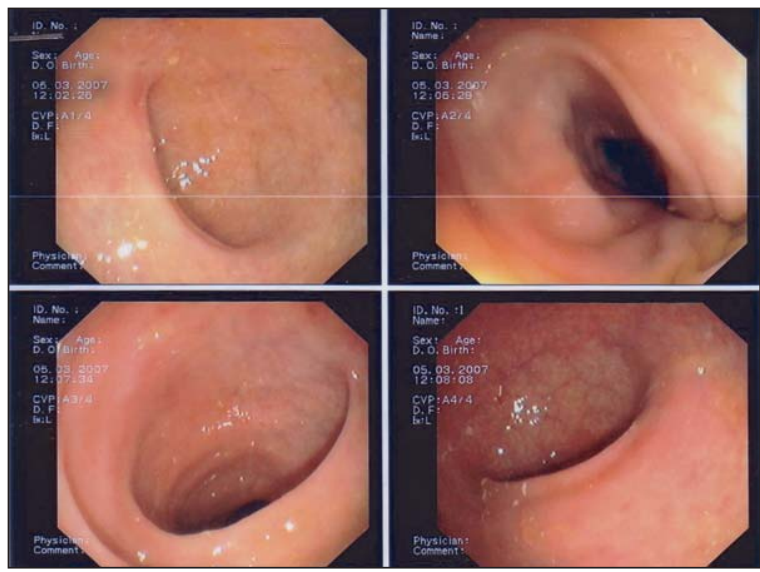

Fig.-2: Colonoscopic findings after treatment with steroid

\section{Discussion}

HSP is a vasculitis syndrome comprising of characteristic skin rash, abdominal colic, joint pain and renal involvement. Previously it was known as anaphylactoid purpura ${ }^{4}$, purpura rheumatica and peliosis rheumatica. ${ }^{5}$

The syndrome is mainly a disease of early childhood with most cases present around 10 years of age. ${ }^{6}$ It is infrequent in adults over the age of 20, though HSP in a lady of 81 years old has been documented. ${ }^{7}$ Males are affected as twice as females ${ }^{5}$. HSP in elderly women at the age of her 65 is a rare entity worth reporting. Recent history of respiratory tract infection was reported in $90 \%$ of cases as is in our case. ${ }^{6}$ Any of the four major components of the syndrome may present in advance of the other but renal disease usually presents late. ${ }^{5}$

Classical vasculitis rash appears over the extensor surfaces of arms and legs and over the buttocks and elbows. However it had been reported that abdominal and chest wall involvement occurred in $54 \%$ of cases. ${ }^{8}$ Individual lesions are mostly less than $1 \mathrm{~cm}$ in diameter but they may coalesce to form large discolored patches and disappearing over two weeks. In more severe cases, hemorrhagic, pupuric or necrotic lesions may be prominent. It becomes then mandatory to differentiate these lesions from those of meningococcal septicemia, or other septic emboli or toxic vasculitides, such as seen with drug reactions. ${ }^{9}$

Joint involvement occurs in $60-84 \%$ of cases ${ }^{10}$ and generally affects ankles and knees. It is the most incapacitating part of the illness though may be transient and leave no permanent deformity. ${ }^{11}$ Children usually had large joint involvement but in adults involvement of the small joints is common. ${ }^{8}$

Gastrointestinal disease occurs in up to $70 \%$ of patients ${ }^{10}$ varying from colicky abdominal pain, nausea and vomiting to intestinal hemorrhage, intussusceptions, pancreatitis and hydrops of gall bladder. More than $30 \%$ of patients experienced diffuse abdominal pain as described as bowel angina typically occurring after meal and accompanied by bloody diarrhea. Occasionally, the abdominal symptoms may mimic an acute surgical abdomen. Though adult HSP is said to be characterized by lower frequency of abdominal pain but extensive bowl infarction has been reported. ${ }^{12}$ The extensive lower GI hemorrhage due to colitis associated with vasculitis in the reported case is an uncommon presentation of HSP in a woman of this age group. There is increased risk of renal disease in those patients with bloody stools. ${ }^{13}$

The reported incidence of renal disease ranges from $20-100 \% .^{14}$ Renal involvement is often more 
common and more severe in adult. ${ }^{15}$ In $80 \%$ of those with renal involvement, it becomes apparent within the first four weeks of illness. The remainder predominantly occurs over the next two months although a few are further delayed. ${ }^{16}$ Haematuria with or without protienuria is the most common symptom. Acute nephritic syndrome may be associated with renal insufficiency, Nephrotic syndrome or both. The case in vignette had minimal renal impairment indicating good prognosis. ${ }^{12}$

Direct immunofluroscence in case of HSP shows IgA dominant immune deposit affecting small vessels and differentiates vasculitis of HSP from microscopic polyangitis or hypersensitivity vasculitis which may also present as palpable purpura. The presence of $\operatorname{IgA}$ deposits should be interpreted only in combination with clinical criteria since the former are not unique to HSP and can be seen in a variety of clinical situation in different inflammatory and neoplastic process.

There is no specific treatment for HSP. Bed rest and supportive care such as adequate hydration, are helpful.$^{7}$ NSAID can relieve joint and soft tissue discomfort although there are some controversy as it may affect the renal function. Corticosteroids have some use in severe cases especially for patients with severe abdominal pain. However corticosteroids are not routinely recommended for treatment of rash, joint pain and renal disease alone. Corticosteroids administered during acute phase help to ameliorate the symptoms of severe abdominal pain, arthralgia, and may prevent progression of renal disease in some cases. It is important to recognize the parvovirus B-19 related cases as the treatment is intravenous $\operatorname{IgG}$ and IFN alpha but not the immunosuppressive therapy. In the absence of renal and central nervous system involvement the prognosis for patients with HSP are excellent. One half of the patients experience recurrence. A long term follow up is necessary for patients with renal disease as long term renal complication occurs in $5 \%$ of patients. ${ }^{17}$ Though adult HSP represents a more severe clinical syndrome with worse outcome, ${ }^{18}$ the reported case responded well to intravenous methyl prednisolone and hydrocortisone.

\section{Conclusion:}

Henoch-Schonlein Purpura is a vasculitis syndrome that can present with extensive skin lesions and profuse lower GI bleeding even in the very elderly women and responds well to intravenous steroid therapy.

\section{References}

1. Jennet JC, Falk RJ. Small vessel vasculitis. N Eng J Med 1997; 337:1512-23

2. Sinha A, Sood J, Kumar VP. Henoch-Schonlein purpura and Anesthesia- A case report. Indian J Anaesth 2005; 49(1): 47-48

3. Trujillo H, Guansekaran TS, Eisenberg GM, Pojman D, Kallen R. Henoch- Schonlein purpura: A diagnosis not to be forgotten. J Family Practice 1996; 495-98

4. Lie JT. Illustrated histopathologic classification criteria for selected vasculitis syndromes. Arthritis \& Rheumatism 1990; 33(8): 1074-1087

5. Haycock GB. The nephritis of Henoch-Schonlein purpura. In: Cameron, Davision, Grunfeld, Kerr, Ritz, eds. Oxford Textbook of Clinical Nephrology. Volume 1: Oxford Medical Publications. 1992: 595-612

6. Patrignelli R, Sheikh SH, Shaw- Stiffel TA. HenochSchonlein purpura - A multisystem disease also seen in adults. Post Grad Med 1995; 97(5): 123-134

7. Mak SK, Au Sy. Henoch-Schonlein purpura in an elderly lady: A case report and literature review. Journal of the Hong Kong Geriatrics Society 1999; 9:23-28

8. Han Y, Naparstek Y. Schonlein- Henoch syndrome in adults and children. Seminars in Arthritis and Rheumatism 1991; 21(2):103-109

9. Miller ML, Pachman LM. Vasculitis syndrome. In: Behman RE, Kligeman RM, Arvin AM, eds. Nelson Textbook of Paediatrics.15th ed. Philadelphia: Saunders, 1996:677-8

10. Tizard EJ. Henoch-Schonlein purpura. Arch Dis Child.1999; 80:380-383

11. Schumacher HR Jr. Primer on the rheumatic diseases. 9th ed. Atlanta, Ga: Arthritis Foundation.1988:164-5

12. Carmichael P, Brun E, Jayawardane S, Abdulkadir A, O'Donnell PJ. A fatal case of bowel and cardiac involvement in Henoch Schonlein purpura. Nephrol Dial Transplant 2002; 17:497- 499

13. Lanzkowsky S, Lanzkowsky L, Lanzkowsky P. Henoch Schonlein Purpura. Paediatr Rev 1992; 13:130-7

14. Meadow SR. The prognosis of Henoch-Schonlein purpura in adult. Clin Nephrol 1978; 9:87-90

15. Ly MN, Breza Jr TS. Henoch-Schonlein purpura in an adult. Skin Med 2003; 2(4):262-4

16. Blotch DA, Michel BA, Hunder GU. The American College of Rheumatology 1990 criteria for classification of vasculitis patients and methods. Arthritis Rheumatism 1990; 33(8): 1068-1073

17. Kraft DM, Denise Mckee D, Scott C. Henoch-Schonlein purpura: A Review. American Family Physician. 1998; 58(2):1-6

18. Pillebout E, Thervet E, Hill G, Alberti C, Vanhille P, Nochy D. Henoch- Schonlein purpura in adults : outcome and prognostic factors. J Am Nephrol 2002; 13(5):1271-8. 